\title{
Generic prescribing for children
}

\author{
Sri Lanka Journal of Child Health, 2008; 37: 36-7
}

(Key words: Generic prescribing, children)

Drugs that are used to treat illnesses have been discovered, formulated and released for general use following a rigorous process of testing for quality, stability, biological efficacy and safety. It is well known that out of the multitude of chemical or biological compounds that enter the starting point of the process, only a very small number ultimately reach the shelves for approved use. Very large amounts of money are spent by pharmaceutical organisations in research and development of new drugs that finally reach the patient. Each "discovery" is put through numerous animal and human trials before it is certified and registered for general use. The original discoverers of the drug usually obtain a time-limited patent on the compound, during which time the rights of manufacture are granted exclusively to just one institution. Usually the drug is marketed under a "trade name" or "brand name" that is unique to that compound.

Once the time period of the patent has expired other manufacturers are at liberty to make and distribute the drug in question. These may be released under different trade names or under "generic names". A generic drug is one which is produced and distributed without patent protection $^{1}$. The generic drug may still have a patent on the formulation but not on the active ingredient. A generic must contain the same active ingredients as the original formulation. In most cases, it is considered bioequivalent to the brand name counterpart with respect to pharmacokinetic and pharmacodynamic properties. By extension, therefore, generics are assumed to be identical in dose, strength, route of administration, safety, efficacy, and intended use. In most cases, generic products are not available until the patent protections afforded to the original developer have expired. When generic products become available, the market competition often leads to substantially lower prices for both the original brand name product and the generic forms. The time it takes a generic drug to appear on the market varies. Drug patents give twenty years of protection, but they are applied for before clinical trials begin, so the effective life of a drug patent tends to be between seven and twelve years.

Generic drugs are less expensive because generic manufacturers don't have the investment costs of the developer of a new drug. New drugs are developed under patent protection. The patent protects the investment-including research, development, marketing, and promotion-by giving the company the sole right to sell the drug while it is in effect. As patents near expiration, manufacturers can apply to the Food and Drugs Authority (FDA) to sell generic versions. Because those manufacturers don't have the same development costs, they can sell their product at substantial discounts. Also, once generic drugs are approved, there is greater competition, which keeps the price down. Today, almost half of all prescriptions are filled with generic drugs.

It is quite true to say that the original brand name drugs are quite expensive. The exclusive right of production empowers the manufacturer to determine the price structure, taking into account the enormous expenditure of research and development of drugs. Once the patent has expired and other sources get into the scene, prices invariably come down almost purely as a result of marketing competition. The generic formulations are generally the cheapest of all these formulations.

In a scenario of the availability of rigorous quality control and post-marketing surveillance, prescribing in generic formats is perhaps a very desirable way of treating patients. The stringent control procedures ensure that the very best pharmacological preparations are made available. Such a situation is existent in many developed countries as they are geared for strict quality control. In most of the hospitals and other medical institutions of such countries, just a few brands of a given drug are available and prescribing is by generic name. The common misconception that the generic drugs are generally inferior, are made in poor quality facilities and take longer to work are generally debunked, at least in the $\mathrm{USA}^{2}$. Generic prescribing in the UK is about $70 \%{ }^{3}$.

However, generic substitution is a pharmacistinitiated act by which a different brand or an unbranded drug product is dispensed instead of a drug brand that was prescribed by the physician. This means substituting the same chemical entity in the same dosage form for one marketed by a different company. Therapeutic substitution is a pharmacist-initiated act by which a pharmaceutical or therapeutic alternate for the physician-prescribed drug is dispensed without consulting the physician. 
This denotes replacement of the prescribed drug with a chemically different drug within the same therapeutic category, eg, hydrochlorothiazide for frusemide, ranitidine for cimetidine or even chloramphenicol for erythromycin ${ }^{4}$. However, the Scottish Intercollegiate Guideline Network (SIGN) and The National Institute for Health and Clinical Excellence (NICE) have categorically stated that generic substitution is not advisable for antiepileptic drugs for children ${ }^{5}$.

However, if sophisticated facilities are not available for intensive and continuous monitoring of the quality of drugs, a country has to rely on information made available through testing in other countries. This obviously tends to leave the door open for the entry of sub-standard drugs into the market. This scenario is further compromised by the advent of fake and counterfeit drugs, particularly into Asian markets ${ }^{6}$. This appears to be quite a risk for patients who are prescribed generic drugs.

A lot of interest has been generated in the minds of the public regarding the "Generic vs. Brand" issue as judged by the recent correspondence in the newspapers. In the light of all this, the recent attempts on the part of the authorities in Sri Lanka to bring in legislation to make generic prescribing mandatory for all doctors seems to have many problems. To start with, lack of qualified pharmacists in the pharmacies makes it quite a risky procedure for generic substitution. Be that as it may, the primary major problem is the lack of facilities for adequate quality testing, including bioavailability assessments of generics within the country. Although the authorities seem to have taken into account the strong lobbying by patient interest groups and other interested parties, paediatricians have not been consulted on the implications of the proposed legislative amendments. The responsibilities of those looking after children to their subjects and their parents to provide the best available therapeutic measures have not been taken into account in formulating these laws. Finally, the legal implications of the shouldering of responsibilities by paediatricians in possible cases of "therapeutic failures" due to substandard generics have not been considered at any time. However, sanity has finally prevailed and it is to the eternal credit of the Executive President of Sri Lanka that, in response to the appeals made by other interested non-medical parties, the proposed legislature has been put in abeyance, at least for the time being.

\section{References}

1. Available from http://en.wikipedia.org/wiki/Generic_drug

2. Available from http://www.medicinenet.com/script/main/art.as $\mathrm{p}$ ?articlekey $=46204$

3. Walley T, Burrill. Generic prescribing : time to regulate the market ? BMJ 2000;320:131-2

4. Available from http://aappolicy.aappublications.org/cgi/conten t/abstract/pediatrics;79/5/835

5. Available from http://www.attract.wales.nhs.uk/question_answ ers.cfm?question_id=2006

6. Perera BJC. Fake and counterfeit drugs : An emerging scourge or an established blight? Sri Lanka Journal of Child Health 2007;36:125-6

B J C Perera Joint Editor 